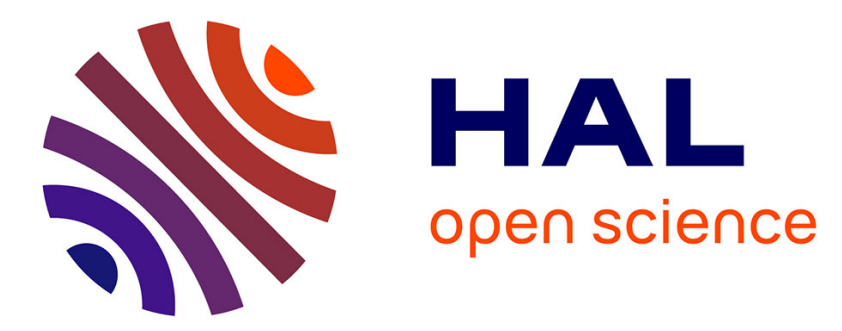

\title{
Indigenous and exogenous organics and surface-atmosphere cycling inferred from carbon and oxygen isotopes at Gale crater
}

H. B. Franz, P. R. Mahaffy, C. R. Webster, G. J. Flesch, E. Raaen, Caroline

Freissinet, S. K. Atreya, C. H. House, A. C. Mcadam, C. A. Knudson, et al.

\section{To cite this version:}

H. B. Franz, P. R. Mahaffy, C. R. Webster, G. J. Flesch, E. Raaen, et al.. Indigenous and exogenous organics and surface-atmosphere cycling inferred from carbon and oxygen isotopes at Gale crater. Nature Astronomy, 2020, 4, pp.526-532. 10.1038/s41550-019-0990-x . insu-02538419

\section{HAL Id: insu-02538419 \\ https://hal-insu.archives-ouvertes.fr/insu-02538419}

Submitted on 18 Dec 2020

HAL is a multi-disciplinary open access archive for the deposit and dissemination of scientific research documents, whether they are published or not. The documents may come from teaching and research institutions in France or abroad, or from public or private research centers.
L'archive ouverte pluridisciplinaire HAL, est destinée au dépôt et à la diffusion de documents scientifiques de niveau recherche, publiés ou non, émanant des établissements d'enseignement et de recherche français ou étrangers, des laboratoires publics ou privés. 


\title{
Indigenous and exogenous organics and surface-atmosphere cycling inferred from carbon and oxygen isotopes at Gale crater
}

\author{
H. B. Franz ${ }^{1 \star}$, P. R. Mahaffy ${ }^{1}$, C. R. Webster ${ }^{2}$, G. J. Flesch², E. Raaen ${ }^{1}$, C. Freissinet ${ }^{3}$, S. K. Atreya ${ }^{4}$, \\ C. H. House ${ }^{\circledR 5}$, A. C. McAdam 1, C. A. Knudson ${ }^{1,6}$, P. D. Archer Jr. ${ }^{7,8}$, J. C. Stern ${ }^{1}$, A. Steele ${ }^{9}$, \\ B. Sutter,8, J. L. Eigenbrode ${ }^{10}{ }^{1}$, D. P. Glavin ${ }^{1}{ }^{1}$, J. M. T. Lewis ${ }^{1,10}$, C. A. Malespin', M. Millan ${ }^{1,11}$, \\ D. W. Ming ${ }^{7}$, R. Navarro-González ${ }^{12}$ and R. E. Summons ${ }^{13}$
}

Since landing at Gale crater, Mars, in August 2012, the Curiosity rover has searched for evidence of past habitability, such as organic compounds, which have proved elusive to previous missions. We report results from pyrolysis experiments by Curiosity's Sample Analysis at Mars (SAM) instrument, focusing on the isotopic compositions of evolved $\mathrm{CO}_{2}$ and $\mathrm{O}_{2}$, which provide clues to the identities and origins of carbon- and oxygen-bearing phases in surface materials. We find that $\mathrm{O}_{2}$ is enriched in ${ }^{18} \mathrm{O}$ $\left(\delta^{18} \mathrm{O}\right.$ about $40 \%$ ). Its behaviour reflects the presence of oxychlorine compounds at the Martian surface, common to aeolian and sedimentary deposits. Peak temperatures and isotope ratios $\left(\delta^{18} \mathrm{O}\right.$ from $-61 \pm 4 \%$ to $64 \pm 7 \%$; $\delta^{13} \mathrm{C}$ from $-25 \pm 20 \%$ to $56 \pm 11 \%$ ) of evolved $\mathrm{CO}_{2}$ indicate the presence of carbon in multiple phases. We suggest that some organic compounds reflect exogenous input from meteorites and interplanetary dust, while others could derive from in situ formation processes on Mars, such as abiotic photosynthesis or electrochemical reduction of $\mathrm{CO}_{2}$. The observed carbonate abundances could reflect a sink for about 425-640 millibar of atmospheric $\mathrm{CO}_{2}$, while an additional 100-170 millibar could be stored in oxalates formed at the surface. In addition, oxygen isotope ratios of putative carbonates suggest the possibility of widespread cryogenic carbonate formation during a previous era.

B ecause the climate of Mars may have been more compatible with life in the ancient past, a key focus of Mars exploration has involved the search for organic compounds that could have supported an ancient Martian biosphere. Curiosity's SAM instrument, which studies volatile compounds in scooped and drilled samples from the Martian surface, has detected several lines of evidence for organic carbon in Gale crater, including ion fragments typical of aliphatic and aromatic hydrocarbons as well as chlorobenzene, dichloroalkanes and thiophenes ${ }^{1,2}$. Over geologic time, organic compounds may be transformed to metastable intermediates such as oxalate and acetate that accumulate at the surface and are detectable by SAM ${ }^{3,4}$. The abundance of carbon associated with these compounds in SAM data is substantially greater than that estimated for exogenous organic matter, implying in situ formation mechanisms (see Supplementary Information). In addition to organic compounds, SAM has detected potential evidence for carbonate in some samples ${ }^{5}$, which could reflect a surface sink for $\mathrm{CO}_{2}$ from a thicker ancient atmosphere ${ }^{6}$.

SAM carries two instruments-a quadrupole mass spectrometer (QMS) and a tunable laser spectrometer (TLS)-that measure isotope ratios in Martian volatile compounds. Measurements of Martian atmospheric $\mathrm{CO}_{2}$ by both instruments have revealed isotopic enrichment in carbon and oxygen, with ${ }^{13} \mathrm{C} /{ }^{12} \mathrm{C}$ of atmospheric carbon elevated by about $60 \%$ or more compared to carbon from the Martian mantle $e^{7,8}$. The isotopic composition of $\mathrm{CO}_{2}$ evolved from samples as they are heated can offer insights into carbon and oxygen sources and communication between atmospheric and surface volatile reservoirs.

\section{Samples and analytical results}

The samples discussed here represent both aeolian deposits and sedimentary rocks within Gale crater, investigated during an approximately 19.5-km-long traverse from November 2012 to November 2017 that climbed approximately $375 \mathrm{~m}$ in elevation. Ten samples acquired by Curiosity's drill and three obtained by scooping of aeolian deposits yielded robust measurements of $\mathrm{CO}_{2}$ isotopic composition. One drilled sample and one aeolian sample also yielded isotopic analyses of $\mathrm{O}_{2}$. The geological context for these samples, identified in Fig. 1, is described in the Supplementary Information.

Carbon and oxygen isotope ratios $\left(\delta^{13} \mathrm{C}\right.$ and $\left.\delta^{18} \mathrm{O}\right)$ for evolved $\mathrm{CO}_{2}$ and $\mathrm{O}_{2}$ as measured by the QMS are reported in Supplementary Tables 1 and 2, while $\mathrm{CO}_{2}$ and $\mathrm{O}_{2}$ release profiles are shown in Extended Data Fig. 1. Uncertainties $( \pm 1 \sigma)$ represent the standard error of the mean for isotope ratios near peak maximum.

'NASA Goddard Space Flight Center, Greenbelt, MD, USA. 'Jet Propulsion Laboratory, California Institute of Technology, Pasadena, CA, USA. ${ }^{3}$ LATMOSIPSL/CNRS, University of Versailles St Quentin, Guyancourt, France. ${ }^{4}$ Department of Climate and Space Sciences, University of Michigan, Ann Arbor, MI, USA. ${ }^{5}$ Department of Geosciences, Pennsylvania State University, University Park, PA, USA. ${ }^{6}$ Department of Astronomy, University of Maryland, College Park, MD, USA. ${ }^{7}$ NASA Johnson Space Center, Houston, TX, USA. ${ }^{8}$ Jacobs Technology, Houston, TX, USA. ${ }^{9}$ Geophysical Laboratory, Carnegie Institute of Washington, Washington, DC, USA. ${ }^{10}$ Universities Space Research Association, Columbia, MD, USA. "'Department of Biology, STIA, Georgetown University, Washington, DC, USA. ${ }^{12}$ Instituto de Ciencias Nucleares, Universidad Nacional Autonoma de Mexico, Cuidad Universitaria, Mexico City, Mexico. ${ }^{13}$ Department of Earth, Atmospheric and Planetary Sciences, Massachusetts Institute of Technology, Cambridge, MA, USA.

*e-mail: heather.b.franz@nasa.gov 


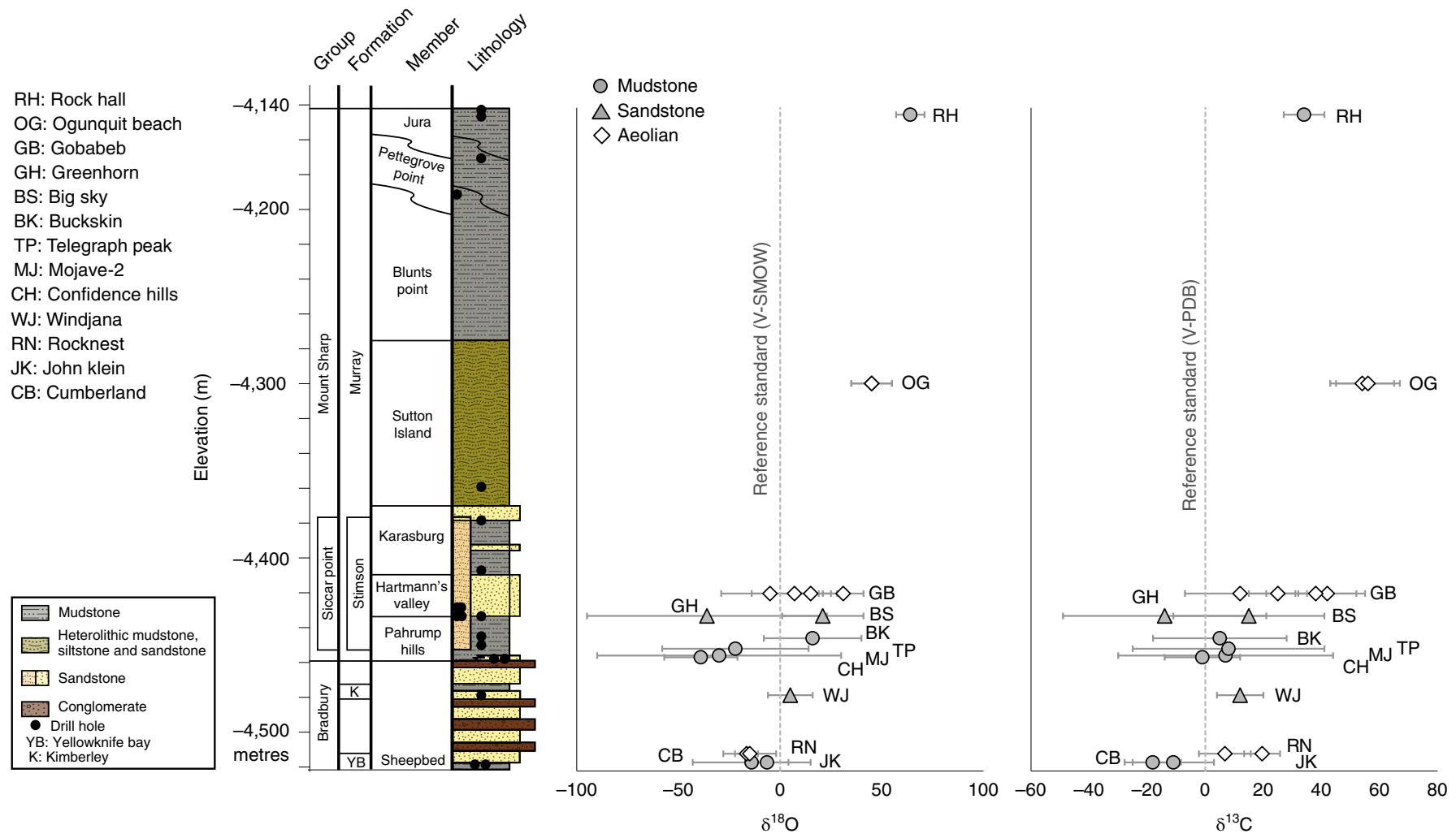

Fig. 1 $\mathrm{CO}_{2}$ isotopic composition displayed in stratigraphic context. The $y$-axis gives the elevation from the reference areoid, shown here as a proxy for the thickness of rock observed. Samples were acquired from various geologic members, which are subunits of formations, the fundamental lithostratigraphic units. Formations related by lithology, lateral continuity or other similarities may be organized into groups as shown. The stratigraphic column was prepared by the MSL Sedimentology and Stratigraphy Working Group. Vienna Standard Mean Ocean Water (V-SMOW) and Vienna Pee Dee Belemnite (V-PDB) are the reference standards for the oxygen and carbon isotopes, respectively ${ }^{51}$. The error bars are $1 \sigma$.

Supplementary Table 1 also includes isotope data obtained with the TLS for a subset of samples, with the TLS temperature cut in column 4. 'Temperature cut' refers to a range of temperatures as the oven is ramping during which a portion of the gas stream is collected by the TLS for analysis. The $\mathrm{CO}_{2}$ isotopic composition of each sample is plotted in stratigraphic context in Fig. $1 . \mathrm{CO}_{2}$ shows carbon isotope ratios spanning the range between compositions similar to those of Martian mantle carbon and atmospheric $\mathrm{CO}_{2}$. Oxygen isotope ratios of evolved $\mathrm{CO}_{2}$ show a similar range of fractionation with respect to the terrestrial oxygen isotope standard, and $\mathrm{O}_{2}$ released from oxychlorine compounds has ${ }^{18} \mathrm{O}$ enrichment approaching that of atmospheric $\mathrm{CO}_{2}$. Weighted averages for $\delta^{18} \mathrm{O}$ of $\mathrm{O}_{2}$ evolved from

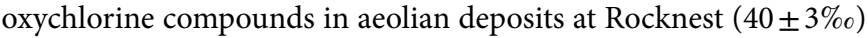
and the Cumberland mudstone $(41 \pm 4 \%$ ) were in close agreement. These results indicate activity of geochemical cycling on Mars that has facilitated transfer between surface and atmospheric reservoirs of carbon and oxygen.

\section{Potential sources of evolved $\mathrm{CO}_{2}$}

Potential known sources of $\mathrm{CO}_{2}$ released during SAM experiments include instrument background from $\mathrm{N}$-methyl- $\mathrm{N}$-(tertbutyldimethylsilyl)-trifluoroacetamide (MTBSTFA) products $\left(\delta^{13} \mathrm{C}\right.$ of $-35 \%$ ) , adsorbed atmospheric $\mathrm{CO}_{2}\left(\delta^{18} \mathrm{O}\right.$ about $50 \%$ and $\delta^{13} \mathrm{C}$ about $\left.45 \% o^{7}\right)$, magmatic carbon $\left(\delta^{13} \mathrm{C}\right.$ of $\left.-19 \pm 4.5 \% 0^{8}\right)$, carbonates, and exogenous carbon from meteorites and interplanetary dust. As discussed in the Methods, combustion of instrument background components should primarily contribute to $\mathrm{CO}_{2}$ evolved below around $150^{\circ} \mathrm{C}$, well below the major $\mathrm{CO}_{2}$ releases, and corrections for isobaric interferences from known MTBSTFA products minimize effects on computed isotope ratios. Adsorbed atmospheric $\mathrm{CO}_{2}$ evolves for a similar temperature range and should also have minimal effects on isotopic compositions obtained for most samples. However, results for $\mathrm{CO}_{2}$ peaks below $200^{\circ} \mathrm{C}$ are reported in the Supplementary Information but are not included in the main discussion because they are likely to include indeterminate contributions from these sources.

A graph of $\delta^{18} \mathrm{O}$ and $\delta^{13} \mathrm{C}$ measured by SAM versus $\mathrm{CO}_{2}$ peak temperature (Fig. 2) suggests that the data fall into three general groups: (I) a low-temperature group (Yellowknife Bay) with depletions in both ${ }^{18} \mathrm{O}$ and ${ }^{13} \mathrm{C}$; (II) a mid-temperature group (Rocknest, Murray formation, and Stimson formation) with depletions in ${ }^{18} \mathrm{O}$ (except at Big Sky) but some enrichment in ${ }^{13} \mathrm{C}$; and (III) a hightemperature group (Bagnold dunes) enriched in both ${ }^{18} \mathrm{O}$ and ${ }^{13} \mathrm{C}$. These relationships suggest differences in sources of carbon and oxygen among the groups. Referring to Extended Data Fig. 2, $\mathrm{CO}_{2}$ peaks at low and medium temperatures suggest evolution from salts of organic acids or oxalates, while high-temperature peaks are consistent with evolution from Fe or Mg carbonates. The Rock Hall sample was unique in evolving isotopically enriched $\mathrm{CO}_{2}$ at low temperature, with possible reasons offered below. Results for individual samples are discussed in the Supplementary Information.

\section{Potential isotopic fractionation mechanisms}

Fractionation by atmospheric escape. Collective isotopic data for Martian atmospheric gases suggest that Mars lost most of its primordial atmosphere owing to hydrodynamic escape prior to about 4.3 billion years ago ${ }^{9}$ and that evolution of the atmosphere since that time has been driven by a combination of replenishment by volcanic 


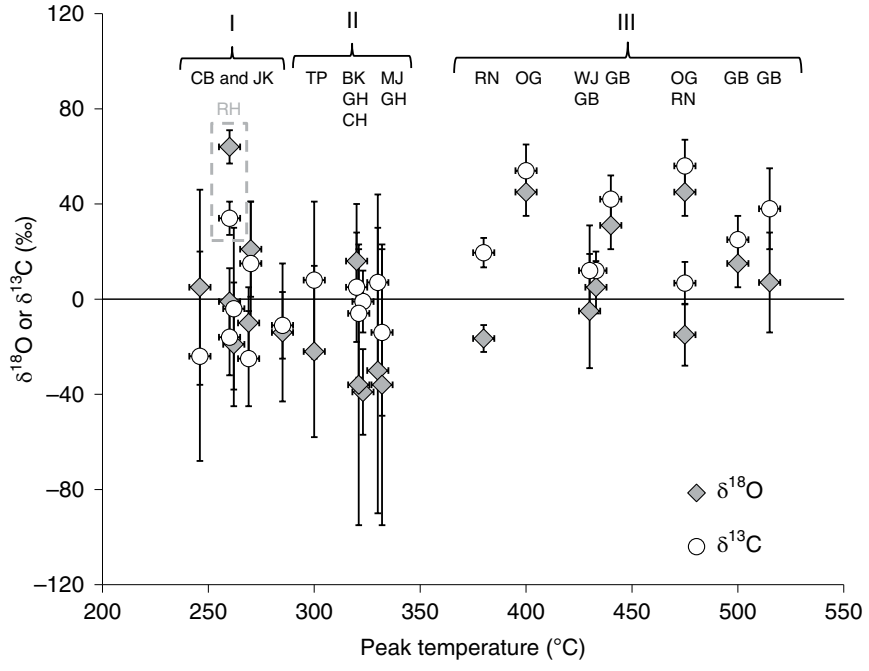

Fig. $2 \mid \mathrm{CO}_{2}$ isotopic composition $\left(\delta^{18} \mathrm{O}\right.$ and $\delta^{13} \mathrm{C}$ ) versus associated evolved gas analysis (EGA) sample peak temperature. Brackets denote general sample groupings (I-III) as discussed in the main text. Sample abbreviations are given in Fig. 1. The Rock Hall ( $\mathrm{RH})$ sample was unique in evolving isotopically enriched $\mathrm{CO}_{2}$ at low temperature and thus does not fit with the Yellowknife Bay samples in group I. The error bars are $1 \sigma$.

outgassing and loss by ongoing escape to space ${ }^{7,10-12}$, formation of carbonates and possibly other minerals at the surface ${ }^{6,13-17}$, and sequestration in various regolith ice deposits ${ }^{9,18-22}$. The continuous loss of gases from the exosphere of Mars to space, facilitated by the absence of a planetary magnetic field ${ }^{23}$, favours the loss of isotopically light species and leaves the remaining atmosphere enriched in heavy isotopes ${ }^{18}$. In the absence of exchange with surface reservoirs, operation of this process over billions of years would generate gradually increasing values of $\delta^{13} \mathrm{C}$ and $\delta^{18} \mathrm{O}$ in atmospheric gases. Although the exact trajectory of $\delta^{13} \mathrm{C}$ and $\delta^{18} \mathrm{O}$ through history is uncertain, outgassing, mineral and ice formation, and isotopic exchange with surface reservoirs have also clearly influenced the isotopic composition of the modern atmosphere. We broadly assume that the net $\delta^{13} \mathrm{C}$ and $\delta^{18} \mathrm{O}$ of Martian atmospheric $\mathrm{CO}_{2}, \mathrm{O}_{2}$ and water have risen over geologic time, such that the modern composition is more isotopically enriched than the ancient composition. The net fractionation due to atmospheric loss throughout the history of Mars is greater than fractionations caused by other processes that we discuss.

Formation of secondary carbonates. Carbonates have been proposed as a sink for atmospheric $\mathrm{CO}_{2}$, and limited evidence for carbonate minerals has been detected at Gale crater by Curiosity's Chemistry and Mineralogy (CheMin) instrument ${ }^{24}$ and globally in thermal emission spectra by orbiting spacecraft ${ }^{25}$. The ${ }^{13} \mathrm{C}$ enrichment observed by SAM in aeolian samples (around 7-56\%o), which evolved $\mathrm{CO}_{2}$ at temperatures consistent with siderite, is within the range of that observed in most carbonates in Martian meteorites (about 7-65\%o) ${ }^{26,27}$. Most studies reporting ${ }^{13} \mathrm{C}$-enriched carbonates have concluded that they formed at low temperatures from fluids influenced by an atmosphere enriched in ${ }^{13} \mathrm{C}$ and ${ }^{18} \mathrm{O}$ through escape processes. For reference, magnesite or siderite forming in isotopic equilibrium with the current atmosphere at $25^{\circ} \mathrm{C}$ would have $\delta^{13} \mathrm{C}$ of $50-60 \%$ and would be about $3 \%$ higher at $0{ }^{\circ} \mathrm{C}$ (ref. ${ }^{28}$ ). The observed values of $\delta^{13} \mathrm{C}$ could be achieved by carbonate precipitation from a reservoir depleted in ${ }^{13} \mathrm{C}$ relative to the modern atmosphere-for example, fluid from which carbonates had already precipitated-or by carbonate formation earlier in Mars' history, when atmospheric $\mathrm{CO}_{2}$ was less isotopically depleted. Earlier episodes of carbonate formation probably would have occurred during the Noachian period, before extensive volcanism produced aerosols that acidified surface waters ${ }^{29}$. Minor contributions to hightemperature $\mathrm{CO}_{2}$ peaks from combustion of ${ }^{13} \mathrm{C}$-depleted organic compounds would also lower $\delta^{13} \mathrm{C}$.

The ${ }^{18} \mathrm{O}$ enrichment observed in $\mathrm{CO}_{2}$ evolved from samples of the Bagnold dunes $\left(\delta^{18} \mathrm{O}\right.$ about $-5 \%$ o to $43 \%$ ) is also similar to that in meteorite carbonates $\left(\delta^{18} \mathrm{O} \sim 1 \% \text { o to } 32 \% 0\right)^{30}$. The fractionation factor for siderite precipitation at $25^{\circ} \mathrm{C}$ predicts an ${ }^{18} \mathrm{O}$ enrichment of around $10 \%$ with respect to $\mathrm{CO}_{2}$ (ref. ${ }^{31}$ ). Carbonates formed in equilibrium with the modern Martian atmosphere thus would have $\delta^{18} \mathrm{O}$ above that observed in meteorites and some Gobabeb peaks, suggesting that the fluids from which at least a portion of the carbonates at Gobabeb formed either had been buffered by silicates or had been isotopically fractionated by freezing or mineral precipitation. On Earth, an effective fractionation constant of $2 \%$ to $3 \%$ o between sea water and ice preferentially partitions ${ }^{18} \mathrm{O}$ into the solid phase, leaving the remaining sea water depleted in ${ }^{18} \mathrm{O}\left(\right.$ ref. ${ }^{32}$ ). Carbonates and sulfates substantially depleted in ${ }^{18} \mathrm{O}$ compared to sea water are common in isolated Antarctic basins, producing progressively depleted brines through Rayleigh distillation during gradual freezing ${ }^{33}$. Morphological observations suggest that some areas of Gale crater may have hosted lakes partially or totally covered by ice during the Hesperian period or later ${ }^{34}$. Alternatively, ${ }^{18} \mathrm{O}$-depleted carbonates could precipitate from a body of water already fractionated owing to prior mineral formation. At $25^{\circ} \mathrm{C}$, minerals typically carry ${ }^{18} \mathrm{O}$ enrichments of up to about $40 \%$ o compared to the water from which they precipitate ${ }^{35}$, leaving the remaining water depleted in ${ }^{18} \mathrm{O}$.

Oxidation of carbon-bearing phases. The Martian surface is exposed to reduced carbon delivered both from the Martian mantle through volcanism and from impacting meteorites. Studies of Martian meteorites have revealed organic matter with $\delta^{13} \mathrm{C}$ of $-13 \%$ o to $33 \%$, while impacting meteorites of chondritic composition could deliver organics with $\delta^{13} \mathrm{C}$ from about $-35 \%$ o to $50 \%$ o (see Supplementary Information) $)^{8,36}$. Overlap of $\mathrm{O}_{2}$ and $\mathrm{CO}_{2}$ evolution during SAM analyses of Gale crater samples has prompted suggestions that the $\mathrm{CO}_{2}$ may reflect combustion of organic carbon during pyrolysis. Similar isotopic compositions in $\mathrm{O}_{2}$ released from the Rocknest and Cumberland samples support a potentially widespread occurrence of an oxychlorine component, as proposed on the basis of the common relationship between nitrate and perchlorate abundances observed by SAM in samples of all types ${ }^{37}$. The average $\delta^{18} \mathrm{O}$ (about $40 \%$, Supplementary Table 2) of the $\mathrm{O}_{2}$ shows substantial enrichment in ${ }^{18} \mathrm{O}$ compared to Martian silicates, suggesting the influence of escape processes that are evident in atmospheric $\mathrm{CO}_{2}$, and even greater ${ }^{18} \mathrm{O}$ enrichment compared to the $\mathrm{CO}_{2}$ released from the Rocknest, Yellowknife Bay and Murray formation samples. Combustion would not be expected to introduce large fractionation in oxygen isotopes between $\mathrm{O}_{2}$ and product $\mathrm{CO}_{2}$, suggesting that while combustion of reduced organic matter by $\mathrm{O}_{2}$ from oxychlorine may have occurred, it was not the dominant source of $\mathrm{CO}_{2}$ evolved from most samples.

Another possibility is that $\mathrm{CO}_{2}$ evolved from mudstones represents carbon from various source materials oxidized at the Martian surface rather than in the pyrolysis oven. Several species of oxidants potentially threaten the stability of organic matter on Mars, including perchlorate and other oxychlorine compounds, hydrogen peroxide and superoxide and hydroxyl $(\cdot \mathrm{OH})$ radicals $^{38}$. The longprevailing perspective is that the presence of strong oxidants, as well as ultraviolet radiation, would restrict the residence time of organic matter at the Martian surface and completely prevent its detection by in situ explorers. However, SAM observations interpreted as evidence for organic compounds preserved in minerals suggest that this may not be the case ${ }^{1,2}$. In addition, Benner et al. ${ }^{3}$ identified 
reaction mechanisms by which $\cdot \mathrm{OH}$ attack on organic compounds typical of carbonaceous chondrites would form metastable intermediates, such as mellitic acid, oxalates, and acetates, that could have accumulated over geologic time to levels detectable by SAM. Applin et al. ${ }^{4}$ reported that oxalate minerals, which their experimental results imply would be as stable to ultraviolet radiation at the surface as sulfates and carbonates, would be particularly amenable to accumulation at the surface.

Most studies of organic compound degradation by $\cdot \mathrm{OH}$ radicals have found associated fractionations of carbon isotopes to be $\leq 10 \%$ o (ref. ${ }^{39}$ ), although larger fractionations of up to about $25 \%$ o have been observed in reactions of alkene double bonds with $\cdot \mathrm{OH}$ $\left(\right.$ ref. $\left.{ }^{40}\right)$. Even with the potential for some fractionation during oxidation, the values of $\delta^{13} \mathrm{C}$ measured by SAM fall within the range observed in meteorites of both Martian and non-Martian origin.

Although some precursor compounds in meteoritic organics contain oxygen, the $\delta^{18} \mathrm{O}$ of $\mathrm{CO}_{2}$ released through decarboxylation of oxidative products would probably be dominated by the composition of the oxidant as well as fractionation during oxidation. We assume that kinetic isotope effects during oxidation might introduce some degree of ${ }^{18} \mathrm{O}$ depletion in products compared to the oxidant, which could explain the ${ }^{18} \mathrm{O}$ depletions in $\mathrm{CO}_{2}$ evolved from samples in groups I and II of Fig. 2. Depending on the waterto- $\mathrm{CO}_{2}$ and water-to-rock ratios, water within a lake at Gale crater could be expected to have $\delta^{18} \mathrm{O}$ of about $5-10 \%$ (ref. ${ }^{31}$ ), requiring ${ }^{18} \mathrm{O}$ depletion of $10-45 \%$ during aqueous oxidation reactions to reach the compositions observed in mudstones. A more depleted starting composition for water could be obtained through fractionation due to partial freezing or previous mineral precipitation, as discussed above.

Another scenario would involve oxidation of organic matter through surface reactions with adsorbed $\cdot \mathrm{OH}$. Owing to low atmospheric pressure, ultraviolet radiation penetrates the entire Martian atmospheric column, allowing the operation of photochemical processes near the surface that on Earth occur only in the stratosphere. The dominant pathways for formation of $\cdot \mathrm{OH}$ in the Martian atmosphere are the reaction of $\mathrm{HO}_{2}$ with $\mathrm{O}$ atoms and $\mathrm{H}_{2} \mathrm{O}_{2}$ photolysis, both of which are ultimately governed by $\mathrm{H}_{2} \mathrm{O}$ photolysis ${ }^{41}$. Photolysis of ozone and $\mathrm{CO}_{2}$ can generate ${ }^{18} \mathrm{O}$-depleted $\mathrm{O}$ atoms, and photocatalysed or electrochemical reduction of water could favour production of $\cdot \mathrm{OH}$ radicals with light oxygen, which could in turn generate ${ }^{18} \mathrm{O}$-depleted products upon oxidation of organic matter and augment ${ }^{18} \mathrm{O}$ depletion due to kinetic isotope effects during oxidation (see Supplementary Information).

In situ formation of organic compounds. From the evolved $\mathrm{CO}_{2}$ abundances compared to exogenous input, it seems likely that some organic material or oxalates at Gale crater formed in situ on Mars. Fischer-Tropsch-type synthesis may form a variety of hydrocarbons abiotically in terrestrial and extraterrestrial environments. Laboratory studies have shown the products of Fischer-Tropschtype synthesis to include aliphatic hydrocarbons and amino acids, which may be oxidized to more stable compounds at the surface, as just discussed (see Supplementary Information). Organics may also be formed by other mechanisms, potentially even in the modern Martian environment. Numerous organic compounds may be produced through photolytic or catalytic reactions driven by light at ultraviolet and visible wavelengths, including photolysis of waterand-gas mixtures and abiotic photosynthesis, in which reduction of $\mathrm{CO}_{2}$ is photocatalysed at semiconductor mineral surfaces (see Supplementary Information). Similar reactions may occur during electrochemical $\mathrm{CO}_{2}$ reduction, powered by non-solar energy sources $^{42}$. In laboratory studies, products of these processes have included carboxylated compounds such as formic acid, formaldehyde and oxalate as well as methane and alcohols. Ultraviolet irradiation of siderite in the presence of water has also been shown to yield formate, formaldehyde and their derivatives (see Supplementary Information). Many of the compounds produced by the above processes may be oxidized to accumulate as oxalate minerals that would decarboxylate during pyrolysis ${ }^{3,4}$.

During vapour-phase reactions at mineral surfaces, initial adsorption would probably introduce only small isotopic fractionations $(<2 \% o)^{43}$. Although biological photosynthesis is complicated by the involvement of enzymes through multiple steps, at present it offers our best analogue for understanding potential fractionations during photocatalysed reduction of $\mathrm{CO}_{2}$ at mineral surfaces. Assuming similar kinetic isotope effects during the abiotic process predicts products with ${ }^{13} \mathrm{C}$ depletions of up to $20-30 \%$ compared to atmospheric $\mathrm{CO}_{2}$.

The oxygen isotopic compositions of plants are not ideal analogues for abiotic reduction products, but laboratory experiments investigating ultraviolet photocatalytic reduction of $\mathrm{CO}_{2}$ to formic acid showed that water functioned as the electron donor to produce oxygen and organic molecules, similar to plant photosynthesis. If the fractionation associated with this process is similar to that observed in oxidation of water by transition metal ions, which evolved oxygen depleted in ${ }^{18} \mathrm{O}$ by about $29 \%$ compared to water, then with an average atmospheric $\delta^{18} \mathrm{O}$ of around $50 \%$, the oxygen isotopic composition of $\mathrm{CO}_{2}$ reduction products could be expected to have $\delta^{18} \mathrm{O}$ of about $10-20 \%$ (see Supplementary Information). Both $\delta^{13} \mathrm{C}$ and $\delta^{18} \mathrm{O}$ values predicted by analogy to terrestrial photosynthetic processes fall within the range of values measured by SAM, supporting abiotic photosynthesis as a potential source of compounds evolving $\mathrm{CO}_{2}$ at low and medium temperatures.

Implications for the Martian carbon cycle. Carbon-bearing phases detected in Gale crater sediments probably reflect multiple sources and various geochemical processes (Fig. 3), which are relevant to understanding the history of Mars' climate and habitability. SAM observations of $\mathrm{CO}_{2}$ evolved from aeolian deposits at the Bagnold dunes with temperatures and isotope ratios consistent with possible siderite support the formation of carbonates as a surface sink for $\mathrm{CO}_{2}$. The Rock Hall mudstone sample, with $\mathrm{CO}_{2}$ of similar isotopic composition to that from Ogunquit Beach and Gobabeb, was unique in evolving $\mathrm{CO}_{2}$ at a peak temperature of about $260^{\circ} \mathrm{C}$ but enriched in both ${ }^{13} \mathrm{C}$ and ${ }^{18} \mathrm{O}$ and also containing akaganeite at several weight per cent (see Supplementary Information). Laboratory studies have shown that carbonates may evolve $\mathrm{CO}_{2}$ at lower-thannormal temperatures through reaction with $\mathrm{HCl}$ released from akaganeite or oxychlorine compounds, also evident at Rock Hall. It is possible that $\mathrm{CO}_{2}$ evolved from siderite at Rock Hall by this mechanism (see Supplementary Information). If so, carbonate at Rock Hall may reflect a local source for some of that observed at nearby dunes. Overlap in isotopic composition between the two peaks evolved from each Bagnold dune sample would be consistent with two size fractions of Fe-carbonate, a dust component represented by the peak temperature range of about $400-425^{\circ} \mathrm{C}$ and larger grains represented by the peak temperature range of about $475-525^{\circ} \mathrm{C}$. It is notable, however, that the peak temperatures and isotopic composition were similar between the coarse and fine size fractions of the Gobabeb sample, suggesting a common origin for carbonate in these fractions. Given that the larger grains probably represent local rather than global sediments, assignment of the dust fraction to a global component would imply that formation of carbonate occurred by a similar mechanism and under similar conditions at a large scale.

Abundances of $\mathrm{CO}_{2}$ released from the Gobabeb 1 and Ogunquit Beach 3 samples were equivalent to approximately $2.1 \mathrm{wt} \%$ and $1.4 \mathrm{wt} \%$ siderite, respectively. Following the calculations of Bridges et al. ${ }^{44}$, these values would indicate a sink for around $425-640 \mathrm{mb}$ of atmospheric $\mathrm{CO}_{2}$, if the siderite inferred to reside in these samples represents a global component ${ }^{44}$. The isotopic compositions of $\mathrm{CO}_{2}$ 


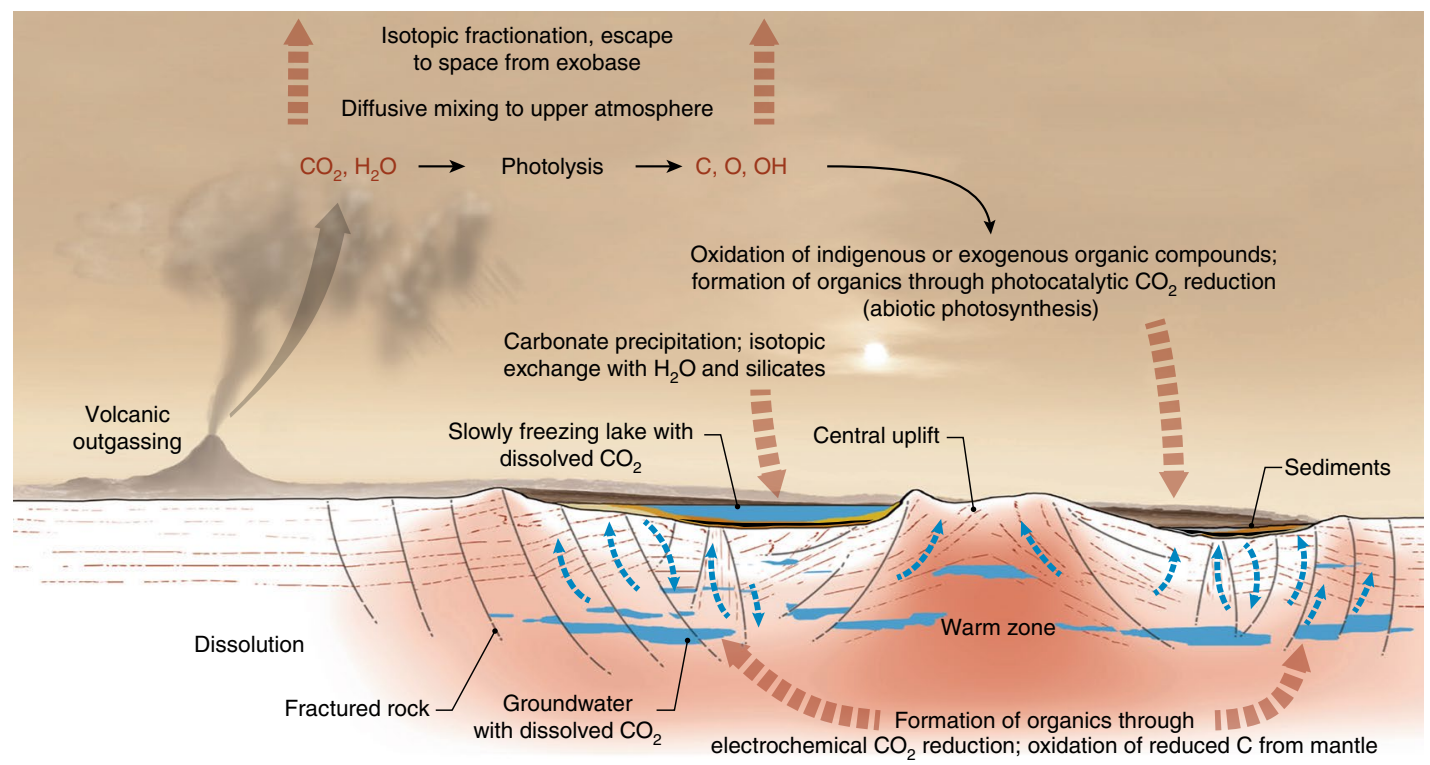

Fig. 3 | Sketch displaying major processes and environments that affected the isotopic composition of carbon and oxygen in Gale crater samples. The details and relevance of each process are discussed in the text. Escape of $\mathrm{CO}_{2}$ to space is an ongoing process that has gradually enriched the atmosphere in heavy isotopes over time. Fractionation due to other processes depicted in the figure is generally overprinted on the signature introduced by atmospheric escape. The blue arrows indicate circulation of ground water, whereas the brown arrows indicate reactions or transport of carbon- and oxygen-bearing phases.

evolved from Gobabeb and Ogunquit Beach, showing enrichments in both ${ }^{18} \mathrm{O}$ and ${ }^{13} \mathrm{C}$, suggest the influence of atmospheric $\mathrm{CO}_{2}$ fractionated by escape of light isotopes to space. However, the values of $\delta^{18} \mathrm{O}$ and $\delta^{13} \mathrm{C}$ for these samples are largely below those expected for formation of carbonate at equilibrium with the modern Martian atmosphere. This suggests either that the siderite formed predominantly during the Noachian period, when atmospheric $\mathrm{CO}_{2}$ was less enriched in heavy isotopes than it is at present, and reflects a source region external to Gale crater, or that it precipitated from fluids isotopically fractionated with respect to the modern atmosphere, such as through partial freezing. If precipitation of carbonates from partially frozen reservoirs were widespread during a previous phase of history, then cryogenic carbonates could comprise a substantial fraction of carbonate inferred to reside in a global dust component. Isotopic analyses of carbonates in aeolian deposits at other sites across Mars are needed to determine whether the composition observed at Gale crater is likely to reflect locally or globally sourced material.

The evolution of $\mathrm{CO}_{2}$ from all samples at temperatures consistent with various types of oxalate minerals could also reflect a sink for atmospheric $\mathrm{CO}_{2}$ through abiotic photosynthesis. The variability in isotopic composition among the peaks of groups I and II (Fig. 2) suggests that probably only a subset of $\mathrm{CO}_{2}$ peaks potentially derived from oxalate could reflect formation from atmospheric $\mathrm{CO}_{2}$. Because the isotopic fractionation and product yields associated with abiotic photosynthesis are at present unknown and may vary depending on the specific catalysts involved, we cannot be certain which samples may preserve evidence of this process or how much atmospheric $\mathrm{CO}_{2}$ may be stored in oxalates within the regolith, but abundances of $\mathrm{CO}_{2}$ from sandstones (Big Sky and Greenhorn) with isotope ratios closest to those predicted by analogy to plant photosynthesis suggest that if this component were globally distributed, it could store an additional $100-170 \mathrm{mb}$ or so of atmospheric $\mathrm{CO}_{2}$. Given that this component was not detected in every sample by SAM, some oxalate could reflect oxidized organic compounds and some could have already degraded, this range represents an upper limit based on current inventory.

In addition to sequestering $\mathrm{CO}_{2}$, abiotic photosynthesis or electrochemical $\mathrm{CO}_{2}$ reduction could yield organic matter of value to chemotrophic organisms, by analogy to terrestrial environments. Electrochemical reduction of $\mathrm{CO}_{2}$ during late-stage igneous or hydrothermal processes has been suggested as a potential source of organic carbon phases in maskelynite inclusions of the Tissint shergottite ${ }^{8}$. SAM has observed ${ }^{34}$ S-depleted $\mathrm{SO}_{2}$ in some mudstones of Yellowknife Bay and the Murray formation, interpreted to reflect Fe-sulfides derived from a hydrothermal system beneath Gale crater ${ }^{45}$ that could also have delivered carbon-bearing compounds to overlying sediments. These compounds, as well as exogenous organic matter from meteorites and interplanetary dust, could contribute to the carbon inventory observed by SAM and to the potential habitability of Mars $^{3}$.

It is feasible that both abiotic photosynthesis and delivery of exogenous material are ongoing on modern Mars, actively replenishing the surface with small quantities of organic compounds. Abiotic photosynthesis could also yield small amounts of methane and contribute to the variability in background methane detected by TLS (see Supplementary Information) ${ }^{46}$. Although the Martian surface is currently inhospitable to Earth-like life, operation of these processes during earlier, more clement periods of Mars' history could have generated compounds useful to support a biosphere. If biological compounds were indeed present, surface/subsurface fluid exchange ${ }^{27,45}$ could have transferred these compounds to better-protected habitats and facilitated their preservation.

\section{Methods}

SAM EGA. SAM can analyse solid Martian samples obtained by drilling into rocks or scooping surface fines. Powdered samples, each with mass $\sim 45 \mathrm{mg}$ to $\sim 135 \mathrm{mg}$, are passed through one of two sieves, either $150 \mu \mathrm{m}$ or $1 \mathrm{~mm}$, before loading into a quartz sample cup. All but one (Gobabeb 2, or "GB2") of the samples analysed by SAM to date have utilized the $150-\mu \mathrm{m}$ sieve. The GB2 sample was processed through a $1-\mathrm{mm}$ sieve. The sample cup is inserted into one of SAM's two pyrolysis ovens, which is first brought to a nominal preheat temperature of $\sim 50^{\circ} \mathrm{C}$ for a duration of $6-12 \mathrm{~min}$, then heated to $\sim 850^{\circ} \mathrm{C}$ at a rate of $35^{\circ} \mathrm{C} \mathrm{min}{ }^{-1}$ under $25 \mathrm{mb}$ He pressure. SAM's first oven (oven-1) has an external temperature sensor and the second (oven-2) has a secondary heater wire in lieu of a temperature sensor. Two models have been utilized to date for the estimation of sample temperature in oven-2 experiments: oven-2_model-1 and oven-2_model-2. Data shown in Extended Data Fig. 1 for experiments 
using oven- 2 were generated with oven- 2 model- 1 , which at present provides the best available estimates of sample temperatures for oven-2. (We note that figures in Sutter et al. ${ }^{5}$ were generated with oven-2_model-2.) Helium carrier gas penetrates the base of the quartz cup, comprising a porous quartz frit, to sweep evolved gases from the oven efficiently. The model-derived He flow rate is 0.8 standard cubic centimetres per minute $(\mathrm{sccm})$. A small portion of the evolved gas is sampled continuously by the QMS throughout the temperature ramp. The QMS scans its entire mass range, from $m / z 2$ to 535 , via a 'smart-scanning' algorithm that optimizes dwell time at masses where signal is detected during each experiment ${ }^{47}$. Evolution peak temperatures for various gases are compared to those of reference materials to constrain parent mineral phases. Integration of the QMS signal over time for a particular $m / z$ value allows quantitative estimation of chemical and isotopic abundances. A portion of the gas stream, parameterized by a desired range of sample temperature, may also be collected during each run for isotopic and abundance analysis of $\mathrm{CO}_{2}, \mathrm{H}_{2} \mathrm{O}$ and $\mathrm{CH}_{4}$ by the TLS or for analysis by the gas chromatograph and QMS.

Extended Data Fig. 2 shows example EGA data obtained with laboratory test stands at Goddard Space Flight Center. The SAM breadboard system includes the prototype QMS for SAM, which is identical to that of the flight model, and a laboratory version of the pyrolysis oven that is easily accessible for loading samples. A second Goddard Space Flight Center test stand includes a Setaram Labsys Evo thermogravimeter/differential scanning calorimeter coupled to a Pfieffer OmniStar QMS. Both systems are operated under conditions that mimic the performance of the SAM flight model. As seen in Extended Data Fig. 2, continuous monitoring of the gases released as a sample is heated during an EGA experiment provides information helpful in determining the mineral and organic content of the sample. Although this technique cannot conclusively identify specific minerals, EGA is a useful diagnostic tool because volatile-bearing minerals typically release gases at characteristic temperatures, dependent on their composition. For example, under SAM operating conditions, $\mathrm{CO}_{2}$ released from Fe-carbonate typically peaks at $\sim 600^{\circ} \mathrm{C}$, while $\mathrm{CO}_{2}$ released from Ca-carbonate peaks at $\sim 740^{\circ} \mathrm{C}$ (Extended Data Fig. 2a). Some carboxylated organic compounds and oxalates release $\mathrm{CO}_{2}$ at temperatures below this, making them candidate sources for the bulk of $\mathrm{CO}_{2}$ observed by SAM (Extended Data Fig. 2b-d).

$\mathrm{CO}_{2}$ isotope ratios. Both carbon and oxygen isotope ratios of $\mathrm{CO}_{2}$ may be calculated from SAM QMS data. The QMS uses electron-impact ionization and a secondary electron multiplier detector, operated in pulse-counting mode. All data are corrected for detector effects and instrument background as the initial step in quantitative analysis ${ }^{47}$. The QMS is operated primarily in 'unit scan' mode, which counts ions only at integer mass-to-charge ratio $\mathrm{m} / \mathrm{z}$ values, during SAM EGA experiments $s^{47}$. $\mathrm{O}_{2}$ isotope ratios are computed from isotopologues at $\mathrm{m} / z 32$ and 34 , with correction for ${ }^{17} \mathrm{O}$ contributions to $\mathrm{m} / z 34$. Owing to isobaric interferences from other compounds at $m / z 12-13$ and $16-18, \mathrm{CO}_{2}$ isotope ratios are in principle calculated from isotopologues at $m / z 44,45$ and 46. However, because the detector is typically saturated during measurements of $\mathrm{m} / z 44$, the signal for this isotopologue usually must be estimated from the doubly charged ion at $\mathrm{m} / z 22$ using the calibration constant determined during pre-launch testing ${ }^{48}$. In some cases, sufficient data are acquired during the $\mathrm{CO}_{2}$ peak to allow calculation of isotope ratios using $\mathrm{m} / \mathrm{z} 44$ (the $\mathrm{RN}$ and JK samples). Unfortunately, low signal at $\mathrm{m} / z 47$ after subtraction of background and correction of isobaric interferences precludes the use of this isotopologue to constrain the $\mathrm{CO}_{2}$ isotopic composition.

Fragments of MTBSTFA-derived products may produce isobaric interferences with the $\mathrm{CO}_{2}$ isotopologues used for isotopic analysis. Data were corrected for estimated contributions from the following compounds identified in EGA and gas chromatograph mass spectrometry data, based on mass spectra published by the National Institute of Standards and Technology: 1,3-ditert-butyl-1,1,3,3tetramethyldisiloxane; tert-butyldimethylsilanol; tert-butyldimethylsilyl fluoride; 2,2,2-trifluoroacetamide; 2,2,2-trifluoro- $N$-methyl-acetamide; trifluoroacetonitrile; and monochlorotrifluoromethane. In most SAM experiments, the combined interferences from these seven compounds affected values of $\delta^{18} \mathrm{O}$ and $\delta^{13} \mathrm{C}$ by $2-3 \%$ or less.

Equations for computing the carbon and oxygen isotope ratios of $\mathrm{CO}_{2}$, which include corrections for isobaric interferences due to various isotopologues, are given by Franz et al. ${ }^{49}$. A value of $0.32 \%$ for $\Delta^{17} \mathrm{O}$, representing the average for Martian silicates ${ }^{50}$, is assumed for all calculations. A small correction of $3 \%$ was applied to values of $\delta^{18} \mathrm{O}$ to account for QMS mass fractionation ${ }^{49}$. Results are reported as delta values $\left(\delta^{13} \mathrm{C}\right.$ and $\left.\delta^{18} \mathrm{O}\right)$, representing per mil deviations from reference standards:

$$
\delta^{13} \mathrm{C}=1,000 \times\left[\left({ }^{13} \mathrm{C} /{ }^{12} \mathrm{C}\right)_{\text {sample }} /\left({ }^{13} \mathrm{C} /{ }^{12} \mathrm{C}\right)_{\mathrm{V}-\mathrm{PDB}}-1\right]
$$

and

$$
\delta^{18} \mathrm{O}=1,000 \times\left[\left({ }^{18} \mathrm{O} /{ }^{16} \mathrm{O}\right)_{\text {sample }} /\left({ }^{18} \mathrm{O} /{ }^{16} \mathrm{O}\right)_{\mathrm{V}-\mathrm{SMOW}}-1\right]
$$

where the reference standard for carbon is V-PDB and that for oxygen is V-SMOW ${ }^{51}$.
Isotope ratios are nominally computed from the ratios of integrated areas under the EGA curve in the time domain for the $m / z$ of interest (Supplementary Fig. 4), although the average of ratios of signal at these isotopologues for the same time range yields nearly identical results. Uncertainties in resulting isotope ratios for a given measurement represent the standard error of the mean for m45/est_m44 and m46/est_m44 during the relevant portion of the $\mathrm{CO}_{2}$ peak.

Supplementary Table 1 also includes isotope data obtained with the TLS for a subset of samples. The sample temperature cut that was directed to the TLS for each sample is noted in column 4 . The TLS utilizes a near-infrared tunable laser diode at $2.78 \mu \mathrm{m}$ to analyse $\mathrm{CO}_{2}$ and $\mathrm{H}_{2} \mathrm{O}$. Abundances and isotope ratios are calculated by comparison of direct absorption lines with the HITRAN 2012 infrared line list ${ }^{52}$, with minor corrections from calibration gas results using isotopic standards. This enables measurement of $\delta^{18} \mathrm{O}, \delta^{13} \mathrm{C}$ and $\delta \mathrm{D}^{10,53}$.

\section{Data availability}

All SAM data are available at NASA’s Planetary Data System.

Received: 12 April 2019; Accepted: 28 November 2019; Published online: 27 January 2020

\section{References}

1. Freissinet, C. et al. Organic molecules in the Sheepbed mudstone, Gale Crater, Mars. J. Geophys. Res. Planets 120, 495-514 (2015).

2. Eigenbrode, J. L. et al. Organic matter preserved in 3-billion-year-old mudstones at Gale crater, Mars. Science 360, 1096-1101 (2018).

3. Benner, S. A., Devine, K. G., Matveeva, L. N. \& Powell, D. H. The missing organic molecules on Mars. Proc. Natl Acad. Sci. USA 97, 2425-2430 (2000).

4. Applin, D. M., Izawa, M. R. M., Cloutis, E. A., Goltz, D. \& Johnson, J. R. Oxalate minerals on Mars? Earth Planet. Sci. Lett. 420, 127-139 (2015).

5. Sutter, B. et al. Evolved gas analyses of sedimentary rocks and eolian sediment in Gale Crater, Mars: results of the Curiosity rover's Sample Analysis at Mars instrument from Yellowknife Bay to the Namib Dune. J. Geophys. Res. Planets 122, 2574-2609 (2017).

6. Pollack, J. B., Kasting, J. F., Richardson, S. M. \& Poliakoff, K. The case for a warm, wet climate on early Mars. Icarus 71, 203-224 (1987).

7. Mahaffy, P. R. et al. Abundance and isotopic composition of gases in the martian atmosphere from the Curiosity rover. Science 341, 263-266 (2013).

8. Steele, A. et al. A reduced organic carbon component in martian basalts. Science 337, 212-215 (2012).

9. Jakosky, B. M. \& Jones, J. H. The history of Martian volatiles. Rev. Geophys. 35, 1-16 (1997).

10. Webster, C. R. et al. Isotope ratios of $\mathrm{H}, \mathrm{C}$, and $\mathrm{O}$ in $\mathrm{CO}_{2}$ and $\mathrm{H}_{2} \mathrm{O}$ of the martian atmosphere. Science 341, 260-263 (2013).

11. Jakosky, B. M. et al. Loss of the Martian atmosphere to space: present-day loss rates determined from MAVEN observations and integrated loss through time. Icarus 315, 146-157 (2018).

12. Atreya, S. K. et al. Primordial argon isotope fractionation in the atmosphere of Mars measured by the SAM instrument on Curiosity and implications for atmospheric loss. Geophys. Res. Lett. 40, 1-5 (2013).

13. Wray, J. J. et al. Orbital evidence for more widespread carbonate-bearing rocks on Mars. J. Geophys. Res. Planets 121, 652-677 (2016).

14. Ehlmann, B. L. et al. Orbital identification of carbonate-bearing rocks on Mars. Science 322, 1828-1832 (2008).

15. Murchie, S. L. et al. A synthesis of Martian aqueous mineralogy after 1 Mars year of observations from the Mars Reconnaissance Orbiter. J. Geophys. Res. Planets 114, E00D06 (2009).

16. Bibring, J. P. et al. Mars surface diversity as revealed by the OMEGA/Mars Express observations. Science 307, 1576-1581 (2005).

17. Christensen, P. R. et al. Mars global surveyor thermal emission spectrometer experiment: investigation description and surface science results. J. Geophys. Res. 106, 23823-23871 (2001).

18. Pepin, R. O. Evolution of the martian atmosphere. Icarus 111, 289-304 (1994).

19. Jakosky, B. M., Pepin, R. O., Johnson, R. E. \& Fox, J. L. Mars atmospheric loss and isotopic fractionation by solar-wind-induced sputtering and photochemical escape. Icarus 111, 271-288 (1994).

20. Pepin, R. O. On the origin and early evolution of terrestrial planet atmospheres and meteoritic values. Icarus 92, 2-79 (1991).

21. Jakosky, B. Mars volatile evolution: evidence from stable isotopes. Icarus $\mathbf{9 4}$, 14-31 (1991).

22. Luhmann, J. G., Johnson, R. E. \& Zhang, M. H. G. Evolutionary impact of sputtering of the martian atmosphere by $\mathrm{O}+$ pickup ions. Geophys. Res. Lett. 19, 2151-2154 (1992).

23. Lundin, R., Lammer, H. \& Ribas, I. Planetary magnetic fields and solar forcing: implications for atmospheric evolution. Space Sci. Rev. 129, 245-278 (2007). 
24. Bristow, T. F. et al. Low Hesperian $P_{\mathrm{CO} 2}$ constrained from in situ mineralogical analysis at Gale Crater, Mars. Proc. Natl Acad. Sci. USA 114, 2166-2170 (2017).

25. Bultel, B., Viennet, J.-C., Poulet, F., Carter, J. \& Werner, S. C. Detection of carbonates in Martian weathering profiles. J. Geophys. Res. Planets 124, 989-1007 (2019).

26. Wright, I. P., Grady, M. M. \& Pillinger, C. T. Carbon, oxygen and nitrogen isotopic compositions of possible Martian weathering products in EETA 79001. Geochim. Cosmochim. Acta 52, 917-924 (1988).

27. Halevy, I., Fischer, W. W. \& Eiler, J. M. Carbonates in the Martian meteorite Allan Hills 84001 formed at $18+/-4$ degrees $C$ in a near-surface aqueous environment. Proc. Natl Acad. Sci. USA 108, 16895-16899 (2011).

28. Deines, P. Carbon isotope effects in carbonate systems. Geochim. Cosmochim. Acta 68, 2659-2679 (2004)

29. Craddock, R. A. \& Greeley, R. Minimum estimates of the amount and timing of gases released into the martian atmosphere from volcanic eruptions. Icarus 204, 512-526 (2009)

30. Valley, J. W. et al. Low-temperature carbonate concretions in the Martian meteorite ALH84001: evidence from stable isotopes and mineralogy. Science 275, 1633-1638 (1997).

31. Chacko, T. \& Deines, P. Theoretical calculation of oxygen isotope fractionation factors in carbonate systems. Geochim. Cosmochim. Acta 72, 3642-3660 (2008).

32. Toyota, T. et al. Oxygen isotope fractionation during the freezing of sea water. J. Glaciol. 59, 697-710 (2013).

33. Staudigel, P. T. et al. Cryogenic brines as diagenetic fluids: reconstructing the diagenetic history of the Victoria Land Basin using clumped isotopes. Geochim. Cosmochim. Acta 224, 154-170 (2018).

34. Fairen, A. G. et al. A cold hydrological system in Gale crater, Mars. Planet. Space Sci. 93-94, 101-118 (2014).

35. Friedman, I. \& O’Neil, J. R. in Data of Geochemistry 6th edn (ed. M. Fleischer) Ch. KK (USGS, 1977).

36. Elsila, J. E., Charnley, S. B., Burton, A. S., Glavin, D. P. \& Dworkin, J. P. Compound-specific carbon, nitrogen, and hydrogen isotopic ratios for amino acids in CM and CR chondrites and their use in evaluating potential formation pathways. Meteorit. Planet. Sci. 47, 1517-1536 (2012).

37. Stern, J. C. et al. The nitrate/(per)chlorate relationship on Mars. Geophys. Res. Lett. 44, 2643-2651 (2017).

38. Lasne, J. et al. Oxidants at the surface of Mars: a review in light of recent exploration results. Astrobiology 16, 977-996 (2016).

39. Davidson, J. A. et al. Carbon kinetic isotope effect in the reaction of $\mathrm{CH}_{4}$ with HO. J. Geophys. Res. Atmos. 92, 2195-2199 (1987)

40. Rudolph, J., Czuba, E. \& Huang, L. The stable carbon isotopic fractionation for reactions of selected hydrocarbons with $\mathrm{OH}$-radicals and its relevance for atmospheric chemistry. J. Geophys. Res. 105, 29329-29346 (2000).

41. Atreya, S. K. \& Gu, Z. G. Photochemistry and stability of the atmosphere of Mars. Adv. Space Res. 16, 657-658 (1995).

42. Hori, Y., Murata, A. \& Yoshinami, Y. Adsorption of CO, intermediately formed in electrochemical reduction of $\mathrm{CO}_{2}$, at a copper electrode. J. Chem. Soc. Faraday Trans. 87, 125 (1991).

43. Rahn, T. \& Eiler, J. M. Experimental constraints on the fractionation of ${ }^{13} \mathrm{C} /{ }^{12} \mathrm{C}$ and ${ }^{18} \mathrm{O} /{ }^{16} \mathrm{O}$ ratios due to adsorption of $\mathrm{CO}_{2}$ on mineral substrates at conditions relevant to the surface of Mars. Geochim. Cosmochim. Acta 65, 839-846 (2001).

44. Bridges, J. C., Hicks, L. J. \& Treiman, A. H. in Volatiles in the Martian Crust (eds J. Filiberto \& S. P. Schwenzer) 89-118 (Elsevier, 2019).

45. Franz, H. B. et al. Large sulfur isotope fractionations in Martian sediments at Gale crater. Nature Geosci. 10, 658-662 (2017).
46. Webster, C. R. et al. Background levels of methane in Mars' atmosphere show strong seasonal variations. Science 360, 1093-1096 (2018).

47. Franz, H. B. et al. Analytical techniques for retrieval of atmospheric composition with the quadrupole mass spectrometer of the Sample Analysis at Mars instrument suite on Mars Science Laboratory. Planet. Space Sci. 96, 99-113 (2014).

48. Franz, H. B. et al. Reevaluated martian atmospheric mixing ratios from the mass spectrometer on the Curiosity rover. Planet. Space Sci. 109-110, 154-158 (2015).

49. Franz, H. B. et al. Initial SAM calibration gas experiments on Mars: quadrupole mass spectrometer results and implications. Planet. Space Sci. 138, 44-54 (2017).

50. Franchi, I. A., Wright, I. P., Sexton, A. S. \& Pillinger, C. T. The oxygenisotopic composition of Earth and Mars. Meteorit. Planet. Sci. 34, 657-661 (1999)

51. Coplen, T. B. New IUPAC guidelines for the reporting of stable hydrogen, carbon, and oxygen isotope-ratio data. J. Res. Natl Inst. Stand. Technol. 100, 285 (1995).

52. Rothman, L. S. et al. The HITRAN2012 molecular spectroscopic database. J. Quant. Spectrosc. Radiat. Trans. 130, 4-50 (2013).

53. Mahaffy, P. R. et al. The imprint of atmospheric evolution in the $\mathrm{D} / \mathrm{H}$ of Hesperian clay minerals on Mars. Science 347, 412-414 (2015).

\section{Acknowledgements}

This work was funded by NASA's Mars Exploration Program. We thank T. B. Griswold for figure production, R. H. Becker for discussion, and the technical team at the NASA Goddard Space Flight Center Planetary Environments Laboratory for laboratory support.

\section{Author contributions}

H.B.F. developed QMS analytical methods, calculated QMS isotope ratios, interpreted results, performed calibration experiments, and wrote the manuscript and the Supplementary Information. C.R.W. and G.L.F. developed TLS analytical methods and calculated TLS isotope ratios. E.R., C.F. and M.M. assisted with QMS data analysis. H.B.F., A.C.McA., C.A.K., P.D.A. and J.M.T.L. performed supporting laboratory experiments. J.C.S. performed ground-truth isotopic analyses of calibrants. All authors participated in discussion of results or editing of the manuscript.

\section{Competing interests}

The authors declare no competing interests

\section{Additional information}

Extended data is available for this paper at https://doi.org/10.1038/s41550-019-0990-x. Supplementary information is available for this paper at https://doi.org/10.1038/ s41550-019-0990-X.

Correspondence and requests for materials should be addressed to H.B.F

Peer review information Nature Astronomy thanks Alberto Fairen and the other, anonymous, reviewer(s) for their contribution to the peer review of this work.

Reprints and permissions information is available at www.nature.com/reprints. Publisher's note Springer Nature remains neutral with regard to jurisdictional claims in published maps and institutional affiliations.

This is a U.S. government work and not under copyright protection in the U.S.; foreign copyright protection may apply 2020 

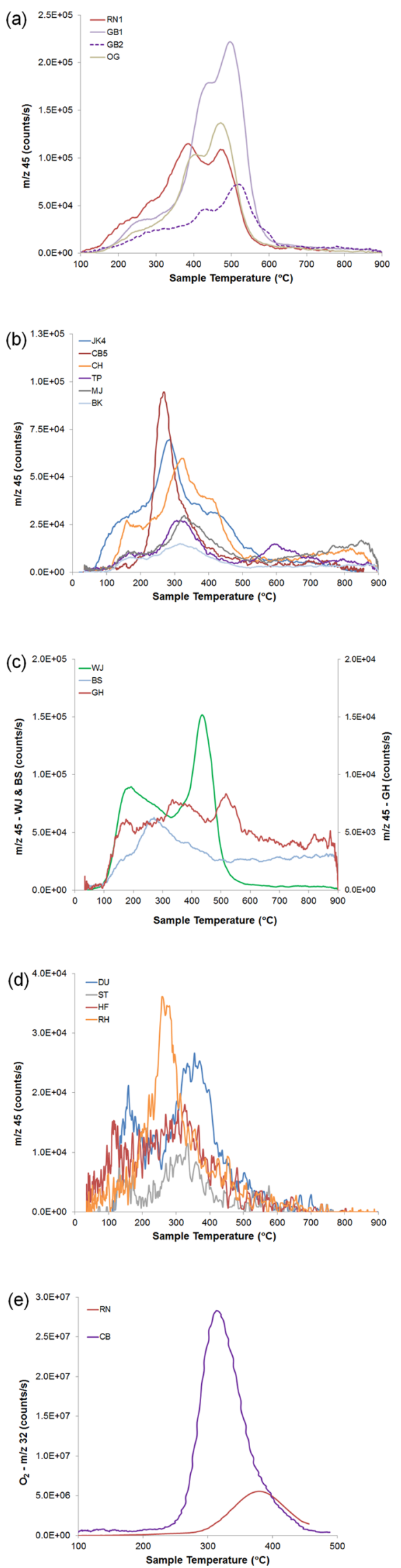

Extended Data Fig. $1 \mid \mathrm{CO}_{2}$ and $\mathrm{O}_{2}$ evolved from Gale crater samples. $\mathrm{CO}_{2}$ (isotopologue at $\mathrm{m} / \mathrm{z} 45$ ) evolved from aeolian (a), mudstone (except Vera Rubin Ridge) (b), sandstone (c) and Vera Rubin Ridge samples (d). e, $\mathrm{O}_{2}$ evolved from RN and CB samples. Data for samples in panels a-c have been normalized to a single portion aliquot. 

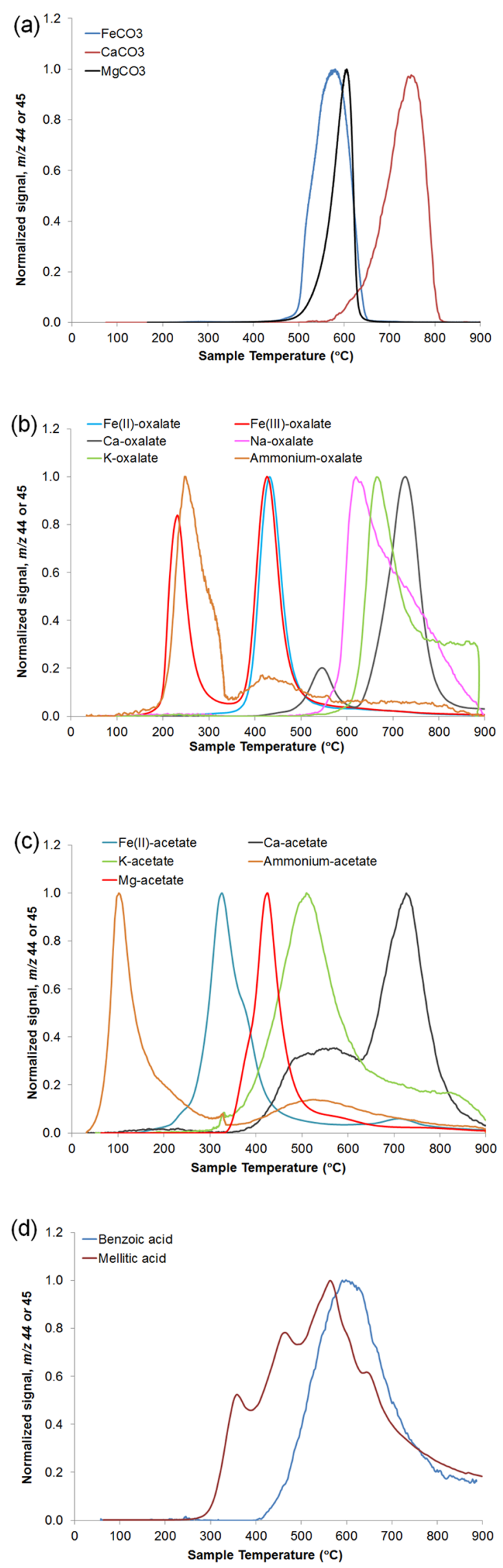

Extended Data Fig. 2 | Laboratory $\mathrm{CO}_{2}$ data. $\mathrm{CO}_{2}$ profile (isotopologue at $\mathrm{m} / \mathrm{z} 44$ or 45) from EGA analyses with laboratory test stands: carbonates (a); oxalates (b); acetates (c); benzoic and mellitic acids (d). The peak temperatures of $\mathrm{CO}_{2}$ evolved from Martian samples by SAM are compared with those from laboratory runs such as these to help identify the mineral phases present. The $\mathrm{CaCO}_{3}$ was the same synthetic material used for SAM flight model calibration. 


\section{Terms and Conditions}

Springer Nature journal content, brought to you courtesy of Springer Nature Customer Service Center GmbH ("Springer Nature").

Springer Nature supports a reasonable amount of sharing of research papers by authors, subscribers and authorised users ("Users"), for smallscale personal, non-commercial use provided that all copyright, trade and service marks and other proprietary notices are maintained. By accessing, sharing, receiving or otherwise using the Springer Nature journal content you agree to these terms of use ("Terms"). For these purposes, Springer Nature considers academic use (by researchers and students) to be non-commercial.

These Terms are supplementary and will apply in addition to any applicable website terms and conditions, a relevant site licence or a personal subscription. These Terms will prevail over any conflict or ambiguity with regards to the relevant terms, a site licence or a personal subscription (to the extent of the conflict or ambiguity only). For Creative Commons-licensed articles, the terms of the Creative Commons license used will apply.

We collect and use personal data to provide access to the Springer Nature journal content. We may also use these personal data internally within ResearchGate and Springer Nature and as agreed share it, in an anonymised way, for purposes of tracking, analysis and reporting. We will not otherwise disclose your personal data outside the ResearchGate or the Springer Nature group of companies unless we have your permission as detailed in the Privacy Policy.

While Users may use the Springer Nature journal content for small scale, personal non-commercial use, it is important to note that Users may not:

1. use such content for the purpose of providing other users with access on a regular or large scale basis or as a means to circumvent access control;

2. use such content where to do so would be considered a criminal or statutory offence in any jurisdiction, or gives rise to civil liability, or is otherwise unlawful;

3. falsely or misleadingly imply or suggest endorsement, approval, sponsorship, or association unless explicitly agreed to by Springer Nature in writing;

4. use bots or other automated methods to access the content or redirect messages

5. override any security feature or exclusionary protocol; or

6. share the content in order to create substitute for Springer Nature products or services or a systematic database of Springer Nature journal content.

In line with the restriction against commercial use, Springer Nature does not permit the creation of a product or service that creates revenue, royalties, rent or income from our content or its inclusion as part of a paid for service or for other commercial gain. Springer Nature journal content cannot be used for inter-library loans and librarians may not upload Springer Nature journal content on a large scale into their, or any other, institutional repository.

These terms of use are reviewed regularly and may be amended at any time. Springer Nature is not obligated to publish any information or content on this website and may remove it or features or functionality at our sole discretion, at any time with or without notice. Springer Nature may revoke this licence to you at any time and remove access to any copies of the Springer Nature journal content which have been saved.

To the fullest extent permitted by law, Springer Nature makes no warranties, representations or guarantees to Users, either express or implied with respect to the Springer nature journal content and all parties disclaim and waive any implied warranties or warranties imposed by law, including merchantability or fitness for any particular purpose.

Please note that these rights do not automatically extend to content, data or other material published by Springer Nature that may be licensed from third parties.

If you would like to use or distribute our Springer Nature journal content to a wider audience or on a regular basis or in any other manner not expressly permitted by these Terms, please contact Springer Nature at

onlineservice@springernature.com 